\section{Myopic foveoschisis: a clinical review}

R Gohil ${ }^{1}$, S Sivaprasad ${ }^{1,2}$, LT Han³ ${ }^{3}$ R Mathew², G Kiousis ${ }^{2}$ and $Y$ Yang ${ }^{4}$

\section{Abstract}

To review the literature on epidemiology, clinical features, diagnostic imaging, natural history, management, therapeutic approaches, and prognosis of myopic foveoschisis. A systematic Pubmed search was conducted using search terms: myopia, myopic, staphyloma, foveoschisis, and myopic foveoschisis. The evidence base for each section was organised and reviewed. Where possible an authors' interpretation or conclusion is provided for each section. The term myopic foveoschisis was first coined in 1999. It is associated with posterior staphyloma in high myopia, and is often asymptomatic initially but progresses slowly, leading to loss of central vision from foveal detachment or macular hole formation. Optical coherence tomography is used to diagnose the splitting of the neural retina into a thicker inner layer and a thinner outer layer, but compound variants of the splits have been identified. Vitrectomy with an internal limiting membrane peel and gas tamponade is the preferred approach for eyes with vision decline. There has been a surge of new information on myopic foveoschisis. Advances in optical coherence tomography will continually improve our understanding of the pathogenesis of retinal splitting, and the mechanisms that lead to macular damage and visual loss. Currently, there is a good level of consensus that surgical intervention should be considered when there is progressive visual decline from myopic foveoschisis.

Eye (2015) 29, 593-601; doi:10.1038/eye.2014.311; published online 6 March 2015

\section{Introduction}

Myopic foveoschisis (MF) is increasingly being recognised as one of the major causes of visual loss in highly myopic eyes. The term myopic foveal retinoschisis was introduced in 1999 by Takano and Kishi to describe the splitting of the inner retinal layers at the macula in patients with high myopia and posterior staphyloma. Although a similar condition was described by
Calbert Phillips in $1958,{ }^{1-3}$ the focus on MF only gained momentum as a well-recognised independent macular complication in this group of patients ${ }^{2-4}$ since the advent of optical coherence tomography (OCT). In particular, spectral domain (SD)-OCT has recently improved our diagnostic accuracy, allowing us to better understand the effects of the various approaches to management of this condition. The majority of publications on $\mathrm{MF}$, to date, have been case series from single centres mainly focussing on clinical aspects of the condition. The purpose of this review article is to amalgamate the various common observations and hypotheses by various authors on $\mathrm{MF}$, and also to highlight any disparity in opinions and observations that may warrant further study. The different approaches to management of MF in the era of time and SD-OCT are also reviewed with particular emphasis on the opinions of the surgical experts on the various techniques used and their success rates.

Epidemiology of high myopia and myopic

There have been no epidemiological studies specifically evaluating the prevalence of MF. Although there are numerous studies on the prevalence of high myopia ascertained using axial length measurement or refraction of adult populations in various countries, only studies that used OCT or colour fundus photography to ascertain the presence of myopic degenerative changes are of relevance to gauge the prevalence of MF. There are no population studies to date that have employed OCT screening to give an accurate estimation of the prevalence of MF. Several recent studies have assessed the occurrence of MF within large groups of selected patients with high myopia.

\section{High myopia}

The prevalence of high myopia has been estimated in large-scale population studies in
${ }^{1}$ NIHR Biomedical Research Centre for Ophthalmology, Moorfields Eye Hospital NHS Foundation Trust, London, UK

${ }^{2}$ Laser and Retinal Research Unit, Department of Ophthalmology, King's College Hospital, London, UK

${ }^{3}$ National Healthcare Group Eye Institute, Tan Tock Seng Hospital, Singapore,

Singapore

${ }^{4}$ Faculty of Life and Health Sciences, Aston University, Birmingham, UK

Correspondence: R Gohil, NIHR Biomedical Research Centre for Ophthalmology, Moorfields Eye Hospital NHS

Foundation Trust, 162 City Road, London EC1V 2PD, UK

Tel: +44 788951 8636;

Fax: +44 20329933738

E-mail: rishma.gohil@ moorfields.nhs.uk

Received: 1 May 2014 Accepted in revised form: 11 November 2014 Published online: 6 March 2015 
China and India. In the Beijing eye study of 3498 patients older than 50 years, using the definition of high myopia as axial length measurement of greater than $26.5 \mathrm{~mm}$, a prevalence of $0.98 \%$ was found..$^{5}$ This is comparable to another similar study in central India, which defined high myopia as having an axial length of greater than $26.5 \mathrm{~mm}$ and found a prevalence rate of $0.53 \%(25 / 4698$ participants). ${ }^{6}$

\section{Myopic maculopathy}

The prevalence of myopic maculopathy in adults has been reported to be in the region of $1-3 \%$ from three recent large-scale population studies looking specifically at the prevalence of myopic maculopathy in adults by employing the use of retinal photography to detect the presence of staphyloma, lacquer cracks, Fuch's spot, and myopic chorioretinal atrophy. ${ }^{7-9}$ In the Handan Eye study of 6830 participants of age 30 years or older, myopic maculopathy was found in 84 individuals giving a person-specific prevalence of $0.9 \% .{ }^{7}$ Using the same method of ascertainment, in the Beijing Eye study, the prevalence of myopic maculopathy in 4439 adults older than 40 years was found to be much higher at $3.1 \% .^{8}$ In the Blue Mountains Eye study, 44 participants out of 3654 participants, mainly of Caucasian racial origin and 49 years or older, had signs of myopic maculopathy on retinal photography, giving a prevalence rate of $1.2 \%{ }^{9}$ The higher prevalence of myopic maculopathy with increasing age in all these studies strongly suggests that myopic maculopathy has a progressive clinical course.

\section{Foveoschisis in myopic eyes}

Several studies have looked at the occurrence of MF in myopic eyes with 8 dioptre sphere or more of myopia. The first study on 32 eyes of 19 patients with severe myopia using time domain OCT reported that 11 eyes had foveal detachment and retinoschisis. ${ }^{10}$ The authors also noted that in 10 eyes the retinoschisis could be visualized, using time domain OCT, as a split into a thicker inner layer and a much thinner outer layer and postulated that the plane of splitting tended to occur between the Henle's fibre layer and the photoreceptor layer.

In 2003, Baba et al studied 134 eyes of 78 patients with high myopia greater than 8 dioptre with OCT and found that all seven eyes with retinoschisis were in the group with staphyloma, but in the group without posterior staphyloma, there were no eyes with retinoschisis. They postulated that foveal detachment and foveoschisis occurred secondarily to scleral enlargement and the inability of the retina to stretch. Interestingly in this study, they found no significant difference in visual acuity between those patients with staphyloma and those without, and observed that some patients with foveal detachment and MF still retained good vision and had not noticed recent symptoms of progressive visual decline. ${ }^{11}$

MF appears to be a common association of high myopia. ${ }^{10,12}$ In 2004, Panozzo et al retrospectively reviewed case notes and graded time domain OCT scans for signs of retinal changes of 218 eyes in 121 patients with myopia of 8-26 dioptre spherical equivalence and found that MF was the most common cause of retinal damage occurring in $34.4 \%$ of eyes followed by other less common causes of retinal damage such as retinal thickening, lamellar hole, and shallow retinal detachment. Again, they also reported that only onethird of patients with macular abnormality were aware of recent visual symptoms. ${ }^{13}$ In 2010, Tang et al ${ }^{14}$ was able to demonstrate the histological changes a clinicopathological case report showing the correlation with the OCT findings and the histological appearances of the intraretinal spaces. In a more recent prospective study using SD-OCT by Henaine-Berra et al, ${ }^{15} \mathrm{MF}$ was identified in 17 of 116 eyes of 72 patients giving a prevalence of $14.65 \%$. These studies, collectively, have shown that in highly myopic eyes with the presence of staphyloma, MF may be an incidental but not uncommon finding that has a slow progression and that patients may remain symptomless. However, due to the lack of a uniformly adopted diagnostic criteria for MF and the paucity of large studies deploying SD-OCT, current prevalence figures for MF may represent an underestimation both in the overall population and also in the stratified population according to increasing age and increasing refractive error.

\section{Diagnosis of MF}

For the diagnosis of MF in myopic eyes, OCT scanning is much more reliable than clinical evaluation based on symptoms and biomicroscopy. In their large case series of patients with high myopia, Panozzo et al ${ }^{13}$ described 25 patients with MF of whom only 15 were symptomatic. This silent and slow nature of the condition, with patients often unaware of the development of MF, was also reported in another large series in 2007 by Gaucher et al. ${ }^{16}$ The macular changes have been reported to be visible on slit lamp biomicroscopy as microcystic appearances and almost always occur in the presence of a posterior staphyloma. Baba et al ${ }^{11}$ when comparing myopic eyes with and without posterior staphyloma observed that MF was only found in the group with posterior staphyloma. Therefore, biomicroscopy findings of otherwise unexplained reduced visual acuity in the presence of a posterior staphyloma, MF should be 
clinically suspected. There is universal agreement between previous studies that OCT should be the main diagnostic tool for confirming the presence of MF. ${ }^{10,11,13}$ The OCT appearances of retinoschisis were first described in detail by Takano and Kishi ${ }^{10}$ in 1999 using time domain OCT. They recognised that retinoschisis was characterised by splitting or formation of an intraretinal cyst separating the retina into a thinner outer layer and a thicker inner layer. There was a high association with a localised posterior retinal detachment. Benhamou et al ${ }^{1}$ also used time domain OCT and described the presence of bridging columns seen between the inner and outer leaves of the split retina (Figure 1). In 2009, Fang et al ${ }^{17}$ used time domain OCT (Zeiss Stratus, Dublin, CA, USA) to describe OCT findings in 18 eyes with MF. They describe a splitting effect of the neural retina, resulting in inner and outer schitic spaces separated by a thin layer of outer neural retina. In the inner schitic space, they observed the presence of intraretinal columns in all eyes with MF. Foveal detachment of both eyes was observed in $72 \%$ of their series, but this extremely high incidence of bilateral foveal detachment may be the result of the concentration effect seen in case series from a single tertiary referral centre. ${ }^{17}$

Using SD-OCT (Zeiss Cirrus), Sayanagi et al ${ }^{18}$ in 2010 found that a three-dimensional macular cube mode of displaying the OCT scans was superior to a one-line or five-line raster scan. They also described the splitting of the neural retina into a thicker inner layer and a very thin outer layer possibly at the level of the external limiting membrane. In many cases, this outer layer was seen to be detached from the RPE line giving the appearance on OCT of a dome-shaped detachment external to a flatter shallow detached inner leaf of the neural retina. Wu Q et $a l^{19}$ in 2011 have reported the occurrence of outer retinal schisis, inner retinal schisis, or compound schisis (when it involved both areas) involving the foveal or non-foveal area, and visual outcome following

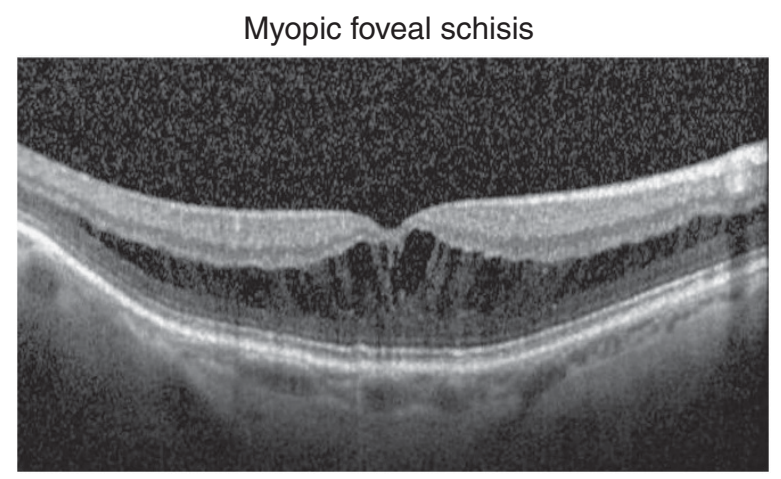

Figure 1 Myopic macular schisis involving the outer plexiform layer (Henle's fibre layer) showing a thick inner layer and thin outer layer. phacoemulsification in myopic eyes (Figure 2). They found that the visual outcome was related to the location and severity of retinoschisis, better in non-foveal compared with foveal schisis. Wang et al in 2012 have studied the SD-OCT features of posterior retinoschisis in high myopia before and after vitrectomy. They report the presence of retinoschisis in the inner, middle, and outer retinal layers, and good visual outcome following internal limiting membrane (ILM) peel. ${ }^{20}$ The other common OCT characteristics described include ILM detachment, epiretinal membranes, retinal microfolds, inner segment/outer segment (equivalent to the ellipsoid zone of the inner segment) line defects, paravascular microholes and macular holes, and patchy or diffuse chorioretinopathy. ${ }^{18,21,22}$ Although SD-OCT is currently the standard tool for diagnosis of $\mathrm{MF}$, newer OCT systems such as swept source OCT have been shown to depict the vitreoretinal interface changes in greater detail. ${ }^{23,24}$ These changes are best visualized using SD-OCT as shown in Figure 1.

\section{Natural history and prognosis}

Longitudinal studies of case series of patients with MF suggest that it is a slowly progressive condition leading to severe central visual loss in untreated cases. The first of such studies by Benhamou et al followed 21 eyes of 17 patients over a period of 1 year. These patients had a diagnosis of MF at baseline on OCT, with a splitting of the neural retina into a thin outer layer and a thicker inner layer joined by axially oriented columns forming

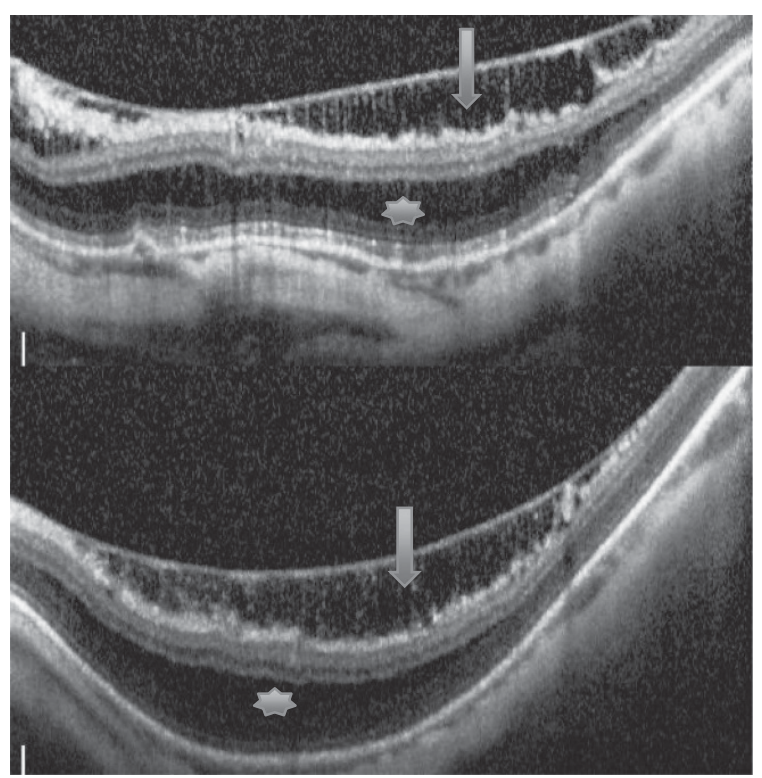

Figure 2 Compound myopic macular schisis involving inner retinal schisis (arrow) and outer retinal schisis (asterisk). 
bridges between the two layers and dividing the outer schitic space into elongated spaces. In five eyes the fovea was involved in the splitting. Seventeen eyes without any visible traction were observed and the majority of them were stable over 1 year, but three eyes had large fluctuations in visual acuity between 20/25 and 20/100 and transient improvement of the retinal splitting. ${ }^{1}$ In 2006, Shimada et $a^{21}$ published a longitudinal study on eight eyes with MF of seven patients followed up for more than 2 years. In their study, two eyes developed macular holes and another two developed retinal detachment, confirming the progressive natural history of MF with macular hole formation being a common cause of visual loss. The mechanism of macular hole formation was suggested to be due to tractional forces from vitreomacular adhesion (Figure 3). In 2007, Gaucher et $a l^{16}$ performed a retrospective case series of 29 eyes and confirmed that the risk of macular hole formation and visual loss was much higher if an epiretinal membrane was visible on OCT causing horizontal or oblique traction. Conversely, they reported that the absence of posterior vitreous detachment confirmed by the absence of a Weiss ring on biomicroscopy, absence of a hyaloid line on OCT, and foveal sparing by the schisis were factors associated with more stability. These characteristics of stability were seen in 9 out of 29 eyes in their series. The majority of eyes $(20 / 29)$ had slow visual decline and progressively severe splitting of the neural retina over a 31-month period.

\section{Pathogenesis of MF}

Several studies suggest that the separation of the retinal layers in MF may be due to inward traction caused in part by a progressive ectasia of the sclera and the relative resistance to a stretch of the inner retinal layers and the retinal vessels. Wu et $a^{25}$ in a cross-sectional study looked at multiple variables in 124 eyes and found that axial length of greater than $31 \mathrm{~mm}$, chorioretinal arophy,

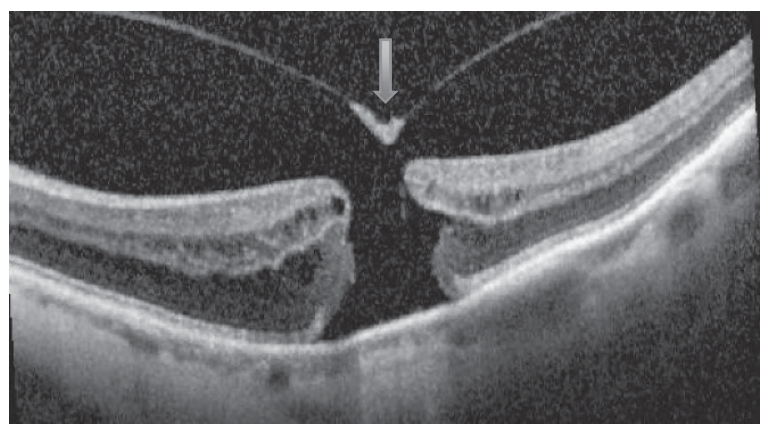

Full thickness myopic macular hole with overlying operculum (arrow)

Figure 3 Full-thickness myopic macular hole with overlying operculum (arrow) in an eye with myopic macular schisis. and vitreoretinal interface factors were independently and significantly associated with the presence of MF in highly myopic eyes. They also found that increasing age and presence of staphylomas showed significant trends in association with MF on univariate analysis. This suggests that the elongation of eyes with age and expansion of the staphylomas could be the mechanism for development of MF. In 1999, Takano and Kishi ${ }^{10}$ prospectively observed 32 eyes in 19 patients with high myopia and found that foveal detachment occurred in $34 \%$ of eyes without macular hole formation, and postulated that the pathogenesis of MF was due to staphyloma progression rather than secondary to fluid recruitment via a macular hole as can occasionally be found in emmetropic eyes. Benhamou et al ${ }^{1}$ noted the absence of pre-retinal structures in 17 of 21 eyes with MF, but also observed that foveal detachment often did not resolve following complete vitrectomy. They concluded from this that vitreous traction was not responsible for the initial development of MF. However, Ikuno et $a l^{2}$ in 2005 studied 21 eyes of 17 patients that had undergone vitrectomy for MF and found the development of microfolds on OCT over a variable period post vitrecomy. They postulated that sclerotic retinal vessels could have prevented the stretching of the retinal layers to maintain retinal adhesion to the RPE, thereby resulting in separation on various cleavage planes and creating the appearance of these microfolds of the neural retina. Another group looked at 239 eyes of 130 patients with high myopia without vitrectomy and found the presence of microfolds related to retinal vessels in $2.9 \%$ of eyes. ${ }^{26}$ This finding was felt to indicate a presence of inward retinal traction in high myopia. In 2004, Bando et al ${ }^{27}$ studied excised membranes from eyes with MF that had undergone ILM peel. They found the presence of collagen fibres and cell debris on inner surfaces of peeled ILM and postulated that fibroblast proliferation may have a role in the pathogenesis of MF. From this body of evidence, it seems that there are two schools of thought on the pathogenesis of MF. Although globe elongation has been shown to be associated with increasing age, axial length in highly myopic eyes tend to stabilise at before 30 years of age, whereas the onset of MF occurs much later in life, typically after 50 years. It is therefore more conceivable that MF changes are due to incomplete or anomalous posterior vitreous detachment combined with contraction of attached cortical vitreous. The tractional forces exerted by the layer of cortical vitreous is probably stronger, given the pre-existing globe ectasia and staphyloma. ${ }^{26-29}$ This in turn leads to separation of the retinal layers in several planes usually at the outer plexiform layer, leaving a thin outer layer and a thicker inner layer. Macular hole formation is probably a secondary phenomenon occurring after a variable period 
of a few months to several years following the development of MF and foveal detachment.

\section{Management}

Numerous publications (Table 1) have described a wide variety of therapeutic interventions for MF.1,4,16,29-43 The main questions to consider when managing a patient with MF are: (i) when should surgical intervention be considered? (ii) Which types of surgical intervention or interventions are most appropriate? (iii) What anatomical and visual outcomes could be expected?

In 1990, Kuriyama and Ogino et al published the outcomes of surgical intervention in 261 eyes in 258 patients with pathological myopia, ${ }^{44}$ retinal detachment, and macular hole, but without peripheral retinal breaks. ${ }^{30}$ These cases preceded the advent of OCT and probably represented late stages of evolution of $\mathrm{MF}$, when posterior pole retinal detachment had occurred secondarily to the macular hole associated with an

Table 1 Management of myopic foveoschisis

\begin{tabular}{|c|c|c|c|c|}
\hline Authors & $\begin{array}{l}\text { Size of } \\
\text { study } \\
\text { (eyes) }\end{array}$ & Techniques used & Results & Complications \\
\hline $\begin{array}{l}\text { Kuriyama } \\
\text { et } a l^{30}\end{array}$ & 261 & $\begin{array}{l}\text { Macular and equatorial } \\
\text { buckling, internal } \\
\text { tamponade } \pm \text { vitrectomy }\end{array}$ & $\begin{array}{l}\text { The final success rates were the same } \\
(95 \%) \text {, regardless of which approach was } \\
\text { selected as an initial technique }\end{array}$ & No known complications \\
\hline $\begin{array}{l}\text { Kobayashi and } \\
\text { Kishi }^{32}\end{array}$ & 9 & $\begin{array}{l}\text { Vitrectomy surgery on } \\
\text { all eyes ( } 6 \text { received gas } \\
\text { tamponade, } 3 \text { did not) }\end{array}$ & $\begin{array}{l}\text { Foveal detachment and retinoschisis } \\
\text { gradually decreased in height in } 8 \text { eyes, } \\
\text { and visual improvement within } 6 \text { months } \\
\text { postoperatively }\end{array}$ & No known complications \\
\hline Ikuno et $a l^{31}$ & 6 & $\begin{array}{l}\text { Vitrectomy with ILM } \\
\text { peeling and gas } \\
\text { tamponade }\end{array}$ & $\begin{array}{l}\text { The foveal detachment resolved } \\
\text { completely in } 5 \text { eyes. BCVA improved } \\
\text { more than two lines in all eyes (100\%) }\end{array}$ & No known complications \\
\hline Kwok et al ${ }^{33}$ & 9 & $\begin{array}{l}\text { Vitrectomy (without } \\
\text { ILM peeling) and gas } \\
\text { tamponade }\end{array}$ & $\begin{array}{l}\text { Median BCVA improved from } 20 / 80 \text { to } \\
20 / 50 \text {. Complete resolution of MF with } \\
\text { complete foveal reattachment in } 77.8 \% \\
\text { with partial resolution in } 22.2 \%\end{array}$ & $\begin{array}{l}\text { Retinal detachment without macular } \\
\text { involvement ( } 1 \text { eye). Visually } \\
\text { significant cataract } 18 \text { months post } \\
\text { surgery ( } 1 \text { eye) }\end{array}$ \\
\hline Gaucher et al ${ }^{16}$ & 11 & $\begin{array}{l}\text { Vitrectomy (without } \\
\text { ILM or gas tamponade) }\end{array}$ & $\begin{array}{l}\text { Foveal reattachment was achieved in } 4 / 11 \\
\text { eyes }\end{array}$ & No known complications \\
\hline Baba et al $l^{11}$ & 5 & $\begin{array}{l}\text { Scleral buckling with a } \\
\text { macular plombe }\end{array}$ & $\begin{array}{l}\text { The mean retinal thickness was reduced } \\
\text { significantly. BCVA was improved by } \\
2 \text { lines or more in } 66 \%\end{array}$ & Subretinal haemorrhage -2 eyes \\
\hline $\begin{array}{l}\text { Sayanagi } \\
\text { et } a^{36}\end{array}$ & 2 & $\begin{array}{l}\text { Vitrectomy with ILM } \\
\text { peel and gas tamponade }\end{array}$ & Successful foveal reattachment in both eyes & No known complications \\
\hline Ikuno et al ${ }^{4}$ & 40 & $\begin{array}{l}\text { Vitrectomy with ILM } \\
\text { peeling and gas } \\
\text { tamponade }\end{array}$ & $\begin{array}{l}\text { The foveal detachment resolved } \\
\text { completely in } 5 \text { eyes and partially in } 1 \text { eye }\end{array}$ & No known complications \\
\hline $\begin{array}{l}\text { Kumagai } \\
\text { et } a l^{37}\end{array}$ & 39 & $\begin{array}{l}\text { Vitrectomy with ILM } \\
\text { peeling and gas } \\
\text { tamponade }\end{array}$ & $\begin{array}{l}70 \% \text { of patients had improved acuity and } \\
\text { all patients had resolution of foveal } \\
\text { detachment }\end{array}$ & No known complications \\
\hline Ji et $a l^{38}$ & 20 & Posterior buckling & $\begin{array}{l}\text { Different degrees of reduction in the split } \\
\text { cavity between inner and outer retinal } \\
\text { layers }\end{array}$ & No known complications \\
\hline Lim $e t a l^{45}$ & 15 & $\begin{array}{l}\text { Vitrectomy with ILM } \\
\text { peeling without gas } \\
\text { tamponade }\end{array}$ & $\begin{array}{l}\text { Postoperatively all eyes achieved foveal } \\
\text { reattachment within } 6 \text { months and } 74 \% \\
\text { (11/15 eyes) had visual improvement }\end{array}$ & No known complications \\
\hline Mateo et $a l^{39}$ & 16 & $\begin{array}{l}\text { Vitrectomy with } \\
\text { macular buckle }\end{array}$ & Improvement in VA in $87.5 \%$ & Progression of $\mathrm{MF}-1$ eye \\
\hline Ikuno et $a l^{4}$ & 8 & $\begin{array}{l}\text { Vitrectomy and ILM } \\
\text { peeling with gas } \\
\text { tamponade }\end{array}$ & $\begin{array}{l}\text { MHs closed } 25 \% \text {. Postoperative BCVA was } \\
\text { significantly correlated with the } \\
\text { preoperative BCVA }(P<0.05)\end{array}$ & $\begin{array}{l}\text { MH size increased significantly in a } \\
\text { case with an unresolved } \mathrm{MH}\end{array}$ \\
\hline Kim et $a l^{42}$ & 17 & $\begin{array}{l}\text { All vitrectomy and ILM } \\
\text { peeling; } 9 \text { with and } 8 \\
\text { without gas tamponade }\end{array}$ & $\begin{array}{l}\text { MF resolved in } 88.9 \% \text { of the gas-treated } \\
\text { group and } 75.0 \% \text { of the no-gas group. } \\
\text { Difference between groups was } \\
\text { statistically insignificant }\end{array}$ & MH formation -2 eyes \\
\hline Ho et $a l^{43}$ & 8 & Victrectomy and ILM & Successful reattachment in 8 eyes $(100 \%)$ & No known complications \\
\hline
\end{tabular}

Abbreviations: BCVA, best corrected visual acuity; FD, foveal detachment; ILM, internal limiting membrane. 
advanced stage of MF. For these advanced cases, using a mixture of external, macular and equatorial buckling, internal tamponade with and without vitrectomy, a reattachment rate of $95 \%$ was achieved. ${ }^{32}$ In 2002, Benhamou et $a l^{1}$ described the evolution of MF using OCT, and described the use of vitrectomy and ILM in three eyes in which vitreous traction was visible on OCT. In 2003, Kobayashi and Kishi, ${ }^{32}$ reported the use of vitectomy in nine eyes of seven highly myopic patients with OCT-confirmed MF. The trigger for surgery in their series was a report of recent visual decline or blurring prior to OCT diagnosis. They achieved resolution of MF in all cases, although the period taken for resolution ranged from 2 months to 21 months. Visual acuity improved by $0.0-0.4$ in six out of seven eyes and decline in one eye due to development of macular hole perioperatively. In 2004, Ikuno et al described their technique of vitrectomy, ILM peel and gas tamponade in six eyes with progressive visual impairment from MF without a macular hole. In their series, all eyes had at least two line improvements at 6 months postoperatively. ${ }^{31}$ In 2005, Kwok and Yip et al also reported a similar series of eight eyes with recent visual loss or central metamorphopsia. ${ }^{33}$ They used vitrectomy without ILM peel and gas tamponade and achieved resolution of MF on OCT in $77.8 \%$ and a mean improvement of 3.6 lines after followup of between 6 and 30 months. In 2007, Gaucher and Gaudric et al studied 29 operated and unoperated eyes. ${ }^{16}$ Eyes that were operated had documented worsening of vision and increasing schisis on OCT prior to surgery. Foveal reattachment was achieved in only four out of 11 eyes that underwent vitrectomy without ILM peel or gas tamponade. In 2006, Baba and Yamamoto et al first described the use of macular plombe designed by Fumitaka Ando to create a posterior buckle for macular hole-related retinal detachment. ${ }^{34,35}$ All five patients had reduced visual acuity pre-operatively between 0.2 and 0.6 and improved by four out of five showing improvement between 0.0 and 0.7 , with OCT showing a resolution of $\mathrm{MF}$ and foveal reattachment after a mean postoperative period of 1.8 months (0.5-3.0 months). In 2006, Sayanagi and Tano et al described successful foveal reattachment in repeat vitrectomy gas tamponade with ILM peel in two eyes, which failed to reattach following initial vitrectomy and gas tamponade without peel. ${ }^{36}$ This suggests the added value of ILM peel for MF. In 2008, Ikuno and Tano et al described 40 eyes with MF undergoing vitrectomy, ILM peel, and gas tamponade. ${ }^{4}$ Their stated indications for surgery were symptoms of visual decline and metamorphopsia, visual acuity of 20/40 or worse, and no major atrophic changes on OCT. All eyes had foveal reattachment postoperatively and final visual acuity was strongly correlated to duration of symptoms and pre-operative acuity, but not age, axial length, or refractive error. ${ }^{4}$ In 2010, Kumagai and Larson et al retrospectively survey 39 eyes that had progressive visual loss due to MF. ${ }^{37}$ Following vitrectomy and ILM peel with gas tamponade, $70 \%$ of patients had improved acuity and all patients had resolution of foveal detachment. In 2011, Ji and Zhang et al retrospectively analysed results of 20 eyes of 15 patients with reduced visual acuity of between 0.4 and 0.04 who underwent posterior buckling for $\mathrm{MF}$, and describe the procedure in detail, but not their rate of foveal reattachment. ${ }^{38}$ In 2012, Lim and Kwon et al evaluated the role of vitrectomy and ILM peel without gas tamponade in 15 eyes of 13 patients with subjective symptoms of progressive visual loss due to MF changes confirmed on OCT. Postoperatively all eyes achieved foveal reattachment within 6 months and $74 \%$ (11/15 eyes) had visual improvement. ${ }^{45}$ In 2012, Mateo and Corcostegui et al described using vitrectomy with a macular buckle in 16 eyes with documented progression on MF and reduced visual acuity, and obtained an improvement in acuity of $87.5 \% .{ }^{39} \mathrm{MF}$ resolution on OCT was achieved in all patients but was observed to occur earlier in those treated with the Ando plombe compared with the hard silicone implant for posterior buckling.

In the above reported studies describing surgical intervention for MF, all authors reported using criteria of progressive visual symptoms, metamorphopsia, and reduction in visual acuity as the main indicators for recommending surgical intervention. Although posterior buckling has been describe in a few studies, the majority of workers used vitrectomy and gas tamponade with or without ILM peel. Using these techniques, foveal reattachment and resolution of MF is usually achieved in all eyes, but full resolution has been reported to take as long as 6 months in some of the studies.

The visual outcome in cases of MF complicated by macular hole formation is more guarded. Ikuno and Tano reported it to be less than $40 \%$ with macular hole closure, and visual improvement after vitrectomy, ILM peel, and gas tamponade was reported to be $40 \%$. The factors that have been found to be correlated with a poorer prognosis by Kumagai and Larson et al in a retrospective study of 39 eyes undergoing vitrectomy and ILM peel were foveal detachment, high axial length, and poor pre-operative visual acuity. ${ }^{37}$ The controversy around the risks of ILM peel was addressed by Zheng and Shen et al in a retrospective series and literature review. ${ }^{41}$ They concluded that vitrectomy and ILM peel did not increase the risk of iatrogenic macular hole formation and that gas tamponade with $\mathrm{C} 3 \mathrm{~F} 8$ resulted in more rapid foveal reattachment and better improvement of visual acuity postoperatively. The advantage of faster resolution using gas tamponade was also shown by Kim and Lee et al in another retrospective study of 17 eyes. ${ }^{42}$ Nevertheless, 
some workers have reported the technique of nonpeeling of residual epifoveolar ILM to further reduce the risk of iatrogenic macular hole formation. Using this technique, Ho and Huang reported successful foveal reattachment in all eight eyes following vitrectomy and limited peel. ${ }^{43}$ This conservative approach may become more popular as the occurrence of postoperative scotomas, postulated to be a result of retinal nerve fibre layer defect or dissociation, is increasingly recognised as a complication of ILM peel. ${ }^{46,47}$

In a recent review of 15 published studies on vitreous surgery in highly myopic eyes with macular holes, Alkabes et $a l^{48}$ concluded that eyes with macular holes associated with foveoschisis required more procedures and also had poorer visual outcomes compared with those without schisis. This observation is in keeping with our own experience (LTH) of vitreous surgery in cases of highly myopic eyes. We have found it useful to subgroup patients according to the presence of visual decline, macular hole, fovea detachment, macular detachment, or foveoschisis or macular schisis. Because of a poorer prognosis when foveoschisis is present especially with an associated macular hole, surgery is reserved only for these patients with progressively declining vision, whereas in patients without schisis but with single-layer macular or foveal detachment, surgery can be considered at an earlier stage prior to further visual decline being documented. In these cases of single-layer macular detachments, we advocate a diligent intraoperative search for eccentric macular holes often located near macular vessels, as these can co-exist with central macular holes and contribute to persistent macular detachment following surgery.

\section{Summary}

MF is not uncommon in patients who have high myopia associated with posterior staphyloma, chorioretinal atrophy, and myopic degeneration. It is likely to be a result of progressive elongation of the myopic globe at a younger age that contributes to the development of abnormal vitreous traction and subsequent anomalous posterior vitreous detachment, which is complicated by splitting of the neural retina and also detachment of the photoreceptors from the RPE. Although readily recognisable on OCT scanning, early diagnosis can often be a challenge as the majority of patients often do not notice any visual symptoms at the time of onset. Visual decline is slow but occurs in the majority of cases. Most reports of surgical approaches used in the management of MF have come from a few specialist centres, indicating the challenging nature of the surgical techniques. Most surgeons would decide to intervene surgically if there is a documentation of decline in visual acuity or recent progression in visual symptoms. The aim of surgery is to release abnormal vitreous traction and to tamponade the posterior retina to restore its attachment with the underlying staphyloma. Currently, this seems to be the most favoured of all the surgical options available, but the techniques and approaches are still evolving as we improve our understanding of the pathogenesis of MF and the factors that can lead to poor therapeutic outcomes, such as nerve fibre layer defects after ILM peel, persistent co-existing eccentric macular holes, and peripheral and posterior breaks, leading to postoperative retinal detachment. However, it is reassuring for patients with MF that in recent years anatomical success of over $80 \%$ has been achieved by refining selection criteria for surgical intervention and using the approach of vitrectomy and gas tamponade coupled with a careful intraoperative search for co-existing eccentric holes and the judicious deployment of ILM peel.

\section{Conflict of interest}

The authors declare no conflict of interest.

\section{Acknowledgements}

The research was supported by the National Institute for Health Research (NIHR) Biomedical Research Centre based at Moorfields Eye Hospital NHS Foundation Trust and UCL Institute of Ophthalmology. The views expressed are those of ours and not necessarily those of the NHS, the NIHR or the Department of Health.

\section{References}

1 Benhamou N, Massin P, Haouchine B, Erginay A, Gaudric A. Macular retinoschisis in highly myopic eyes. Am J Ophthalmol 2002; 133(6): 794-800.

2 Ikuno Y, Gomi F, Tano Y. Potent retinal arteriolar traction as a possible cause of myopic foveoschisis. Am J Ophthalmol 2005; 139(3): 462-467.

3 Philips CI. Retinal detachment at the posterior pole. Br J Ophthalmol 1958; 42(12): 749-753.

4 Ikuno Y, Sayanagi K, Soga K, Oshima Y, Ohji M, Tano Y. Foveal anatomical status and surgical results in vitrectomy for myopic foveoschisis. Jpn J Ophthalmol 2008; 52(4): 269-276.

5 Yin G, Wang YX, Zheng ZY, Yang H, Xu L, Jonas JB et al. Ocular axial length and its associations in Chinese: the Beijing Eye Study. PLoS One 2012; 7(8): e43172.

6 Nangia V, Jonas JB, Sinha A, Matin A, Kulkarni M, Panda-Jonas S. Ocular axial length and its associations in an adult population of central rural India: the Central India Eye and Medical Study. Ophthalmology 2010; 117(7): 1360-1366.

7 Gao LQ, Liu W, Liang YB, Zhang F, Wang JJ, Peng Y et al. Prevalence and characteristics of myopic retinopathy in a rural Chinese adult population: the Handan Eye Study. Arch Ophthalmol 2011; 129(9): 1199-1204. 
8 Liu HH, Xu L, Wang YX, Wang S, You QS, Jonas JB. Prevalence and progression of myopic retinopathy in Chinese adults: the Beijing Eye Study. Ophthalmology 2010; 117(9): 1763-1768.

9 Vongphanit J, Mitchell P, Wang JJ. Prevalence and progression of myopic retinopathy in an older population. Ophthalmology 2002; 109(4): 704-711.

10 Takano M, Kishi S. Foveal retinoschisis and retinal detachment in severely myopic eyes with posterior staphyloma. Am J Ophthalmol 1999; 128(4): 472-476.

11 Baba T, Ohno-Matsui K, Futagami S, Yoshida T, Yasuzumi K, Kojima A et al. Prevalence and characteristics of foveal retinal detachment without macular hole in high myopia. Am J Ophthalmol 2003; 135(3): 338-342.

12 Lin LL, Shih YF, Tsai CB, Chen CJ, Lee LA, Hung PT et al. Epidemiologic study of ocular refraction among schoolchildren in Taiwan in 1995. Optom Vis Sci 1999; 76(5): 275-281.

13 Panozzo G, Mercanti A. Optical coherence tomography findings in myopic traction maculopathy. Arch Ophthalmol 2004; 122(10): 1455-1460.

14 Tang J, Rivers MB, Moshfeghi AA, Flynn HW, Chan CC. Pathology of macular foveoschisis associated with degenerative myopia. J Ophthalmol 2010; 2010: 175613.

15 Henaine-Berra A, Zand-Hadas IM, Fromow-Guerra J, García-Aguirre G. Prevalence of macular anatomic abnormalities in high myopia. Ophthalmic Surg Lasers Imaging Retina 2013; 44(2): 140-144.

16 Gaucher D, Haouchine B, Tadayoni R, Massin P, Erginay A, Benhamou $\mathrm{N}$ et al. Long-term follow-up of high myopic foveoschisis: natural course and surgical outcome. Am J Ophthalmol 2007; 143(3): 455-462.

17 Fang X, Weng Y, Xu S, Chen Z, Liu J, Chen B et al. Optical coherence tomographic characteristics and surgical outcome of eyes with myopic foveoschisis. Eye (Lond) 2009; 23(6): 1336-1342

18 Sayanagi K, Morimoto Y, Ikuno Y, Tano Y. Spectral-domain optical coherence tomographic findings in myopic foveoschisis. Retina 2010; 30(4): 623-628

19 Wu Q, Li SW, Lu B, Wang WQ, Fang J, Yu JY et al. Clinical observation of highly myopic eyes with retinoschisis after phacoemulsification. Zhonghua Yan Ke Za Zhi 2011; 47(4): 303-309.

20 Wang S, Peng Q, Zhao P. SD-OCT use in myopic retinoschisis pre- and post-vitrectomy. Optom Vis Sci 2012; 89(5): 678-683.

21 Shimada N, Ohno-Matsui K, Baba T, Futagami S, Tokoro T, Mochizuki M. Natural course of macular retinoschisis in highly myopic eyes without macular hole or retinal detachment. Am J Ophthalmol 2006; 142(3): 497-500.

22 Sayanagi K, Ikuno Y, Soga K, Tano Y. Photoreceptor inner and outer segment defects in myopic foveoschisis. Am J Ophthalmol 2008; 145(5): 902-908.

23 Lim LS, Cheung G, Lee SY.. Comparison of spectral domain and swept-source optical coherence tomography in pathological myopia. Eye (Lond) 2014; 28(4): 488-491.

24 Itakura H, Kishi S, Li D, Nitta K, Akiyama H. Vitreous changes in high myopia observed by swept-source optical coherence tomography. Invest Ophthalmol Vis Sci 2014; 55(3): 1447-1452.

25 Wu PC, Chen YJ, Chen YH, Chen CH, Shin SJ, Tsai CL et al. Factors associated with foveoschisis and foveal detachment without macular hole in high myopia. Eye (Lond) 2009; 23(2): 356-361.
26 Sayanagi K, Ikuno Y, Gomi F, Tano Y. Retinal vascular microfolds in highly myopic eyes. Am J Ophthalmol 2005; 139(4): 658-663.

27 Bando H, Ikuno Y, Choi JS, Tano Y, Yamanaka I, Ishibashi T. Ultrastructure of internal limiting membrane in myopic foveoschisis. Am J Ophthalmol 2005; 139(1): 197-199.

28 Sebag J. Anomalous posterior vitreous detachment: a unifying concept in vitreo-retinal disease. Graefes Arch Clin Exp Ophthalmol 2004; 242(8): 690-698.

29 Alkabes M, Pichi F, Nucci P, Massaro D, Dutra Medeiros M, Corcostegui B et al. Anatomical and visual outcomes in high myopic macular hole (HM-MH) without retinal detachment: a review. Graefes Arch Clin Exp Ophthalmol 2014; 252(2): 191-199.

30 Kuriyama S, Matsumura M, Harada T, Ishigooka H, Ogino $\mathrm{N}$. Surgical techniques and reattachment rates in retinal detachment due to macular hole. Arch Ophthalmol 1990; 108(11): 1559-1561.

31 Ikuno Y, Sayanagi K, Ohji M, Kamei M, Gomi F, Harino S et al. Vitrectomy and internal limiting membrane peeling for myopic foveoschisis. Am J Ophthalmol 2004; 137(4): 719-724.

32 Kobayashi H, Kishi S. Vitreous surgery for highly myopic eyes with foveal detachment and retinoschisis. Ophthalmology 2003; 110(9): 1702-1707.

33 Kwok AK, Lai TY, Yip WW. Vitrectomy and gas tamponade without internal limiting membrane peeling for myopic foveoschisis. Br J Ophthalmol 2005; 89(9): 1180-1183.

34 Baba T, Tanaka S, Maesawa A, Teramatsu T, Noda Y, Yamamoto S. Scleral buckling with macular plombe for eyes with myopic macular retinoschisis and retinal detachment without macular hole. Am J Ophthalmol 2006; 142(3): 483-487.

35 A Fumitaka. Use of a special macular explant in surgery for retinal detachment with macular hole Jpn. J Ophthalmol 1980; 24: 29-34.

36 Sayanagi K, Ikuno Y, Tano Y. Reoperation for persistent myopic foveoschisis after primary vitrectomy. Am J Ophthalmol 2006; 141(2): 414-417.

37 Kumagai K, Furukawa M, Ogino N, Larson E. Factors correlated with postoperative visual acuity after vitrectomy and internal limiting membrane peeling for myopic foveoschisis. Retina 2010; 30(6): 874-880.

38 Ji X, Wang J, Zhang J, Sun H, Jia X, Zhang W. The effect of posterior scleral reinforcement for high myopia macular splitting. J Int Med Res 2011; 39(2): 662-666.

39 Mateo C, Burés-Jelstrup A, Navarro R, Corcóstegui B. Macular buckling for eyes with myopic foveoschisis secondary to posterior staphyloma. Retina 2012; 32(6): 1121-1128.

40 Ikuno Y, Tano Y. Vitrectomy for macular holes associated with myopic foveoschisis. Am J Ophthalmol 2006; 141(4): 774-776.

41 Zheng B, Chen Y, Zhao Z, Zhang Z, Zheng J, You Y et al. Vitrectomy and internal limiting membrane peeling with perfluoropropane tamponade or balanced saline solution for myopic foveoschisis. Retina 2011; 31(4): 692-701.

42 Kim KS, Lee SB, Lee WK. Vitrectomy and internal limiting membrane peeling with and without gas tamponade for myopic foveoschisis. Am J Ophthalmol 2012; 153(2): 320-6.e1.

43 Ho TC, Chen MS, Huang JS, Shih YF, Ho H, Huang YH. Foveola nonpeeling technique in internal limiting 
membrane peeling of myopic foveoschisis surgery. Retina 2012; 32(3): 631-634.

44 Matsumura N, Ikuno Y, Tano Y. Posterior vitreous detachment and macular hole formation in myopic foveoschisis. Am J Ophthalmol 2004; 138(6): 1071-1073.

45 Lim LS, Mitchell P, Seddon JM, Holz FG, Wong TY. Age-related macular degeneration. Lancet 2012; 379(9827): 1728-1738.

46 Ito Y, Terasaki H, Takahashi A, Yamakoshi T, Kondo M, Nakamura M. Dissociated optic nerve fiber layer appearance after internal limiting membrane peeling for idiopathic macular holes. Ophthalmology 2005; 112(8): 1415-1420.

47 Tadayoni R, Svorenova I, Erginay A, Gaudric A, Massin P. Decreased retinal sensitivity after internal limiting membrane peeling for macular hole surgery. $\mathrm{Br} \mathrm{J}$ Ophthalmol 2012; 96(12): 1513-1516.

48 Alkabes M, Pichi F, Nucci P, Massaro D, Dutra Medeiros M, Corcisteugi B et al. Anatomical and visual outcomes in high myopic macular hole (HM-MH) without retinal detachment: a review. Graefes Arch Clin Exp Ophthalmol 2014; 252(2): 191-199. 